\title{
Development of novel air electrode materials for the SOFC and SOEC technologies
}

\author{
Anna Niemczyk ${ }^{1,2}$, and Konrad Świerczek ${ }^{1,2 *}$ \\ ${ }^{1}$ AGH University of Science and Technology, Faculty of Energy and Fuels, al. A. Mickiewicza 30, \\ 30-059 Krakow, Poland \\ ${ }^{2}$ AGH Centre of Energy, AGH University of Science and Technology, ul. Czarnowiejska 36, \\ 30-054 Krakow, Poland
}

\begin{abstract}
One of major goals in the development of solid oxide fuel cells and its reversible mode, solid oxide electrolyzer cells, is related to a decrease of the operating temperature, down to the intermediate range $\left(600-800{ }^{\circ} \mathrm{C}\right)$ or even lower temperatures. However, this reduction causes an increase of the polarization resistance, especially for the air electrode, which results in a significant decline of the efficiency of the device. Therefore, it is essential to obtain new, thermally and chemically stable materials with the high ionic-electronic conductivity and good catalytic activity for the oxygen reduction reaction working in the decreased temperature range. At the same time, environmental and economic aspects have to be considered in the development of the new compounds. Promising cobalt-free electrode materials can be $\mathrm{Cu}$-based oxides with the perovskite and perovskite-related structures.
\end{abstract}

\section{Introduction}

In the last two decades, a growth of variable renewable energy sources in the total energy mix can be seen markedly. Due to the constantly increasing energy consumption and global consensus about climate changes, most of the governments implemented environmental regulations and put more efforts in the development of new, eco-friendly technologies. Moreover, the large-scale implementation of modern energy solutions in order to minimize the harmful impact on the environment have been undertaken [1,2]. Hydrogen is considered as one of the most promising energy carriers and as a fuel of the future, because of its abundance (although not as pure $\mathrm{H}_{2}$ ), a high energy value and the zero-carbon emission combustion. Therefore, economically and technologically developed European countries, USA, Japan, as well as other developing countries like China, allocate considerable funds for the research on the hydrogen and others so-called clean energy technologies $[3,4]$. The greatest chance for a wide commercialization of the hydrogen-based technologies is associated with fuel cell technology, especially, solid oxide fuel cells (SOFC) and its reversible mode, solid oxide electrolyzer cells (SOEC), in which all parts (anode, electrolyte and cathode) are made of ceramic components [5].

\footnotetext{
* Corresponding author: xi@agh.edu.pl
} 
In this work we discuss issues related to the development of the air electrode materials for SOFCs and SOECs, including a brief introduction of the technology, its possible importance in the energy grids, as well as a description of requirements for the successful air electrode, which have to be fulfilled. Furthermore, a short review of the proposed $\mathrm{Cu}$ based electrode materials (a cathode for SOFC and an anode for SOEC) is presented.

\section{SOFC and SOEC technology}

In relation to the energy production (both, electricity and heat), SOFC technology has gained a lot of attention due to its quite simple operation rules, based on the following steps: 1) oxidation of the fuel at the anode's side, 2) migration of the electric charge (electrons) through the external circuit, 3) migration of the equivalent amount of oxygen ions through electrolyte and 4) the oxygen reduction occurring at the cathode's side, as presented in Fig. 1. The high efficiency of the whole process, up to approx. $70 \%$ or more in cogeneration systems with heat recovery, stems from a fact that the fuel cell converts the chemical energy of a fuel and an oxidant directly into the electrical energy, which is not limited by the Carnot efficiency [6].

a)

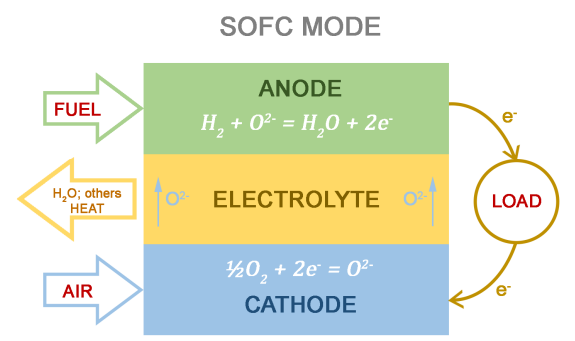

b)

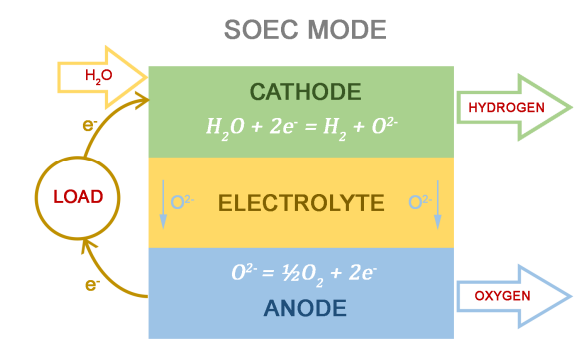

Fig. 1. Scheme of SOFC mode (a) and SOEC mode (b) with major electrodes reactions [5].

A substantial advantage of SOFCs over the other types of the fuel cells is associated with their fuel flexibility, allowing to use fuels other than expensive hydrogen (also hydrogen infrastructure is still undeveloped). Besides, the pure hydrogen, $\mathrm{CH}_{4}, \mathrm{CO}$, jet fuel, methanol, other "dry" hydrocarbons and coal syngas could be used as the fuel [6-8]. Moreover, relatively high operating temperature allows for the internal reforming of the fuel at the anode side, which can be fed with cheap and available conventional fuels like coal, gasoline, ammonia or biomass [9-11]. Apart from the mentioned advantages, SOFCs are quiet, scalable and generally speaking, environmentally friendly $[12,13]$.

As shown in the Fig.1, when the current and $\mathrm{H}_{2} \mathrm{O}$ are applied to the cell, the reversible reactions can take place (SOEC mode) and as a result, we can obtain high-purity hydrogen at the cathode side and oxygen at the anode (air electrode) side. In order to satisfy the increasing demand for hydrogen production, SOEC technology is rapidly developing. Hydrogen production via high-temperature steam electrolysis has attracted great interest in the last years. It can offer higher efficiency, and as a consequence, more favorable thermodynamic and electrochemical kinetic conditions, e.g. operation at temperatures above $600{ }^{\circ} \mathrm{C}$ needs less electrical energy as compared to the conventional low-temperature water electrolysis in proton exchange membrane electrolyzes [14]. Reversible solid oxide cells (rSOCs) may ensure stable energy supply from the renewable energy sources-based plants, becoming the energy storage system. Depending on the needs, rSOC stack can produce electricity working as a fuel cell when the energy demand is high. In the case of excess of the energy production, the device can work in SOEC mode and produce hydrogen for later usage, ergo store energy in a form chemical energy of the produced fuel $[15,16]$. 
Alongside the backup role of the rSOC in the energy grid, SOFCs and SOECs can be applied in various systems: fuel-to-power (SOFC mode), power-to-fuel (SOEC) and others. SOFC stacks play important role in the distributed power generation, as a backup system for private, as well as public sector (schools, hospitals, military) and in the micro cogeneration (combined heat and power, CHP; combined cooling and power, CCP) for residential customers [17,18]. Moreover, stacks can be used in the transport sector (electric buses or cars) instead of the batteries [19]. Recently, an idea of implementation of SOFC systems into big-scale energy plants with gas turbines or/and heat recovery systems has gained attention [20]. Other applications of rSOC are associated with the chemical sector, in which hydrogen can be used inter alia in ammonia or syngas production $\left(\mathrm{CO}_{2}\right.$ can be provided from the conventional power plant), as well as in the steel plants $[6,16,21]$.

\section{Air electrode requirements}

The main trend in SOFC and SOEC development is related to the decrease of the operating temperature below $800{ }^{\circ} \mathrm{C}$ into the so-called intermediate temperature (IT) range $\left(600-800{ }^{\circ} \mathrm{C}\right)$ and even to lower temperatures, in order to eliminate obstacles like the high cost of components, long start-up time, short lifetime, etc., which are consequences of the high operating temperature. Unfortunately, the efficiency of the cells with the commonly used materials deteriorates at lower temperatures, due to the worsened transport properties and lowered catalytic activity. Lowering of the ohmic losses by a decrease of the electrolyte thickness, the development of novel compounds with enhanced properties and transfer to nano-sized materials have been proposed to maintain high efficiency at decreased temperatures $[22,23]$. The polarization of the air electrode is the main source of the cell's performance degradation, and because of that intensive research on the new, highlyefficient SOFC cathode (SOEC anode) materials are currently undertaken [24].

The model air electrode has to meet many requirements, such as a proper porosity to provide a large contact area between the electrode material and gas atmosphere, and a good thermal and mechanical match with others components. Moreover, it should be thermally and chemically stable at operating and preparation temperatures, as well as ought to be inexpensive, easily fabricated and environmentally friendly $[23,25,26]$. Crucial properties of the air electrode are catalytic activity vs. oxygen reduction reaction, ORR, (or oxidation in the SOEC mode), and the high mixed ion-electronic conductivity. ORR is a multistep process, in which each of the steps can be limiting, causing deterioration of the cell's performance $[23,27]$. Oxygen ions migration from the surface to the electrode/electrolyte phase boundary takes place efficiently throughout the entire volume of the electrode only if the electrode material possesses mixed, ionic-electronic type of the conductivity. If the cathode material is a purely electronic conductor, the reaction occurs only at the gaselectrolyte-electrode border (three-phase boundary, TPB) lowering efficiency of the entire process. As mentioned before, an appropriate porosity of the electrode is needed for the effective gas diffusion [27-29]. In the vicinity of the electrode/electrolyte interface, the porosity should disappear to ensure suitable mechanical properties of the interface and improved charge transfer. Good chemical and thermal stability between the electrolyte and the electrode material is required. Typically TECs (thermal expansion coefficient) are in the range of $10-15 \cdot 10^{-6} \mathrm{~K}^{-1}$ in order to avoid excessive stresses [30].

\section{Review of air electrodes materials}

Due to good transport and catalytic properties, originating mainly from the flexibility of cobalt coordination and various redox reactions, cobalt-based oxides with the perovskite 
structure (with $\mathrm{ABO}_{3-\delta}$ formula) or derived structures are widely used as the air electrode materials. A lot of different compositions from e.g. $\mathrm{Ln}_{1-\mathrm{x}}(\mathrm{Ca}, \mathrm{Sr}, \mathrm{Ba})_{\mathrm{x}} \mathrm{Co}_{1-\mathrm{y}} \mathrm{Fe}_{\mathrm{y}} \mathrm{O}_{3-\delta}$ group and $\mathrm{Ln}_{2-\mathrm{x}}(\mathrm{Ca}, \mathrm{Sr}, \mathrm{Ba})_{\mathrm{x}} \mathrm{Co}_{2-\mathrm{y}} \mathrm{M}_{\mathrm{y}} \mathrm{O}_{6-\delta}$ ( $\mathrm{Ln}$ : lanthanides, $\mathrm{M}: 3 \mathrm{~d}$ metals) double perovskites have been investigated. Very promising results in simultaneously both, SOFC and SOEC operation modes, were obtained for $\mathrm{SrCo}_{1-x} \mathrm{Mo}_{x} \mathrm{O}_{3-\delta}$ group, showing low polarization resistance on the order of $0.08-0.13 \Omega \mathrm{cm}^{-2}$ at $750{ }^{\circ} \mathrm{C}$, and also for $\mathrm{La}_{0.8} \mathrm{Sr}_{0.2} \mathrm{Co}_{0.8} \mathrm{Ni}_{0.2} \mathrm{O}_{3-\delta}$, which exhibits good catalytic activity and high electrical conductivity in the wide temperature range [3134]. Tested so far only in SOFC setup, ordered double perovskites, like $\mathrm{GdBaCo}_{2} \mathrm{O}_{5+\delta}$, $\mathrm{PrBaCo}_{2} \mathrm{O}_{5+\delta}$ or similar Mn-doped oxides, show desired transport properties and conductivity (few hundreds of $\mathrm{S} \mathrm{cm}^{-1}$ ), as well as high values of the oxygen ion diffusion coefficient, with reported power densities output exceeding $1 \mathrm{~W} \mathrm{~cm}^{-2}$ at $800^{\circ} \mathrm{C}$ [35-37]. In Fig. 2, area specific resistance (ASR) values are presented as a function of the temperature for different Co-based compositions with perovskite and perovskite-related structures [38].
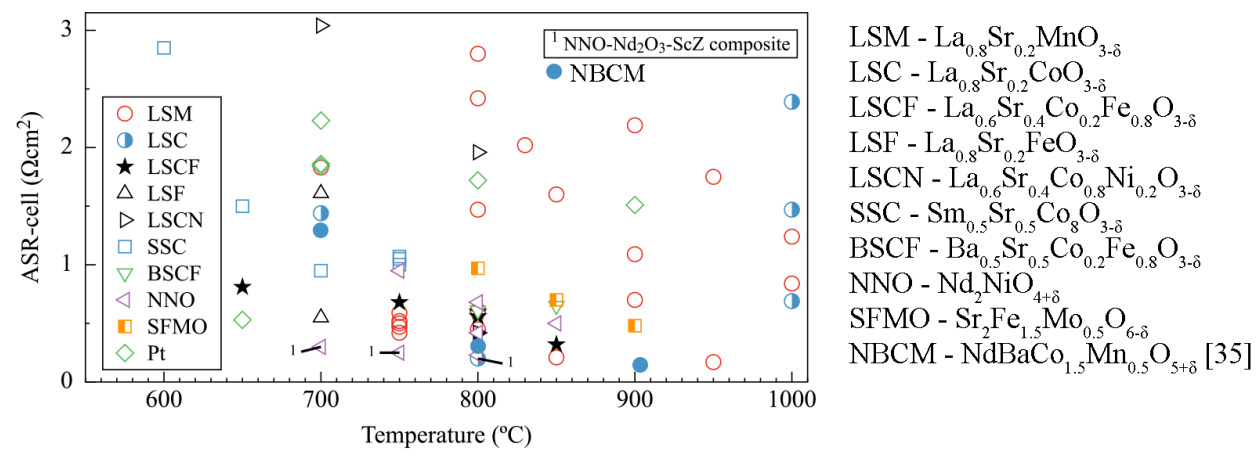

Fig. 2. Comparison of the ASR of selected air electrode as a function of the temperature [38].

Besides Co-based materials, $\mathrm{LaMnO}_{3-\delta}$ and $\mathrm{LaFeO}_{3-\delta}$-related oxides (abbreviated commonly as LSM, LSF, LSCF, etc.) doped in both sublattices, were deeply investigated. The introduced doping stabilizes the cubic structure and enhances the electrochemical performance of the cathode materials (the electronic component of conductivity $\sigma_{\mathrm{e}} \approx 10$ $250 \mathrm{~S} \cdot \mathrm{cm}^{-1}$ at $800{ }^{\circ} \mathrm{C}$ and ionic $\sigma_{\mathrm{i}} \approx 10^{-4}-10^{-7} \mathrm{~S} \cdot \mathrm{cm}^{-1}$ at $800-1000{ }^{\circ} \mathrm{C}$ for the Mn-containing oxides [39]. The established degradation rate in SOFC mode after running more than 19000 $\mathrm{h}$ for LSM was $0.5 \%$ per $1000 \mathrm{~h}$, but in the SOEC mode was close to $20 \%$ [40,41]. Very promising results have been reported for LSF and BSCF air electrodes for rSOC. LSCF is more stable and its degradation rate in the case of SOFC is between $0.6-1.4 \%$ per $1000 \mathrm{~h}$ and for SOEC stack is $5.6 \%$ per $1000 \mathrm{~h}$ after $4000 \mathrm{~h}$ of operation [42-44]. Recently, LópezRobledo et al. presented performance of the LSCF-Ce ${ }_{0.9} \mathrm{Gd}_{0.1} \mathrm{O}_{2-\delta}$ composite in the reversible mode, for which they obtained the highest current densities $0.845 \mathrm{~A} \mathrm{~cm}^{-2}$ at $1.3 \mathrm{~V}$ $\left(800{ }^{\circ} \mathrm{C}\right)$ for microtubular electrolyzer [45]. BSCF, commonly applied in the SOFC stacks, shows low polarization resistance, but its stability in the SOEC conditions is significantly lower compared to the LSC and LSCF [38].

Another group of materials analyzed as potential rSOC air electrode comprises $\mathrm{Ln}_{2} \mathrm{NiO}_{4+\delta}$-based oxides, which demonstrate good electrical conductivity with a promising value of ionic component $\left(\sigma_{\mathrm{i}} \approx 10^{-2} \mathrm{~S} \cdot \mathrm{cm}^{-1}\right.$ in $\left.500-700{ }^{\circ} \mathrm{C}\right)$ and acceptable (in comparison to the conventional cathode materials) electronic conductivity $\left(\sigma_{\mathrm{e}} \approx 10-100 \mathrm{~S} \cdot \mathrm{cm}^{-1}\right.$ at $300-800$ ${ }^{\circ} \mathrm{C}$ ) [39]. Moreover, Ruddlesden-Popper (RP) nickelates present long-term stability and compatibility with commonly used electrolytes [46-48]. Especially good properties in both, SOFC and SOEC mode, shows $\mathrm{Pr}_{2} \mathrm{NiO}_{4+\delta}-\mathrm{Ce}_{0.9} \mathrm{Gd}_{0.1} \mathrm{O}_{2-\delta}$ composite, for which no changes after $100 \mathrm{~h}$ in fuel cell mode were noticed and the current density was $-780 \mathrm{~mA} \mathrm{~cm}^{-2}$ at 1.3 $\mathrm{V}$ at $800{ }^{\circ} \mathrm{C}[46-48]$. 
Recently, in the literature, a transfer from the microscale to the nanoscale materials, including nanosized fibers, shell structures or thin films, can be noticed. It allows to enhance the performance of the well-studied materials (mostly Co-based) in the lowered range of the operating temperatures [49-52]. Nanofiber structures, due to the possibility of fabrication of highly porous electrode layers with continuous pathways for charge collection, enable to reduce the polarization resistance even by one order of magnitude, as reported for BSCF at $550{ }^{\circ} \mathrm{C}$, and almost double power density at $650{ }^{\circ} \mathrm{C}$ of SOFC with LSFC cathode [53,54]. Excellent results, with power density around $2 \mathrm{~W} \mathrm{~cm}^{-2}$ at $550{ }^{\circ} \mathrm{C}$ (pure $\mathrm{H}_{2}$ as fuel), were showed for SOFC consisting of nanocomposite functional anode layers, thin $\mathrm{Ce}_{0.9} \mathrm{Gd}_{0.1} \mathrm{O}_{2-\delta}(\mathrm{CGO})$ electrolyte, and core/shell fiber-structured BSFC-CGO composite. Furthermore, the tested cell presented low voltage degradation around $0.1 \mathrm{mV}$ after $250 \mathrm{~h}$ of operation under high current density $\left(1 \mathrm{~A} \mathrm{~cm}^{-2}\right)$ [54].

\section{Cu-based oxides as the potential air electrodes}

As presented in the section 4, current research on the air electrode for rSOC is mainly focused on the Co-containing systems and optimization of their nano- or microstructure. However, electrodes with Co are characterized by high TEC values (mismatching with typical electrolytes) and as a result, insufficient thermomechanical stability is observed [48]. Moreover, due to toxicity and the high cost of cobalt, research on Co-free air electrode materials is of interest and importance.

Copper-based materials seem to be an interesting alternative, due to the lower costs and high abundance of $\mathrm{Cu}$. Besides, in the literature, there are some reports about $\mathrm{Cu}$-doping enhancing the catalytic activity of SOFC/SOEC electrode materials [55,56]. Copper oxides have gained attention in the $80 \mathrm{~s}$ when Bednorz and Müller announced high-temperature superconductivity in a new group of materials (Ba-La-Cu-O system), for which they received Nobel Price [57]. Many research groups have started the examination of $\mathrm{LaCuO}_{3-\delta}$-based perovskites and layered $\mathrm{La}_{2} \mathrm{CuO}_{4}$-based oxides, mainly in terms of their conductivity, superconductivity and interesting magnetic properties [58-63]. However, until now, studies concerning the application of the cuprates as the air electrodes for SOFCs or SOECs are still limited.

\section{1 $\mathrm{LaCuO}_{3-\delta}$-based SOFC cathodes with perovskite structure}

Due to the extremely high (exceeding $10^{4} \mathrm{~S} \mathrm{~cm}^{-1}$ ), metallic-type electrical conductivity, $\mathrm{LaCuO}_{3}$ oxide seems to be a very promising air electrode candidate. However, the fully stoichiometric $\mathrm{LaCuO}_{3}$, in which all copper cations possess +3 oxidation state, can be only obtained under very high oxygen partial pressure (order of GPa) and crystalizes in the rhombohedral symmetry. Unfortunately, this materials is not stable at the ambient pressure and decomposes to $\mathrm{CuO}$ and $\mathrm{La}_{2} \mathrm{CuO}_{4}[63,64]$. Nevertheless, $\mathrm{LaCuO}_{3-\delta}$ may exhibit high oxygen nonstoichiometry $(0 \leq \delta \leq 0.5)$ in a wide range of the oxygen partial pressures, resulting in a presence of various concentrations of $\mathrm{Cu}^{+2}$ and $\mathrm{Cu}^{+3}$ ions. Interestingly, copper cations might be present in the octahedral coordination, the pyramid with a square base or the square-planar coordination $[65,66]$.

It is known that perovskite structure, as well as large oxygen nonstoichiometry, enable transport of oxygen ions via vacancy mechanism, in which oxygen anions hop between vacancies in the anionic sublattice. The ion conduction is possible in all dimensions and its effectiveness generally increases with the increasing vacancy concentration [67]. Obviously, the mentioned extremely high total electrical conductivity is a result of the dominant electronic contribution, which can be associated with hybridization of $3 d$ orbitals originating from copper and $2 p$ orbitals of oxygen anions in $\mathrm{CuO}_{6}$ octahedra. As 
a consequence, $2 p$-orbitals may effectively overlap with $3 d$-orbitals of transition metal (B, i.e. $\mathrm{Cu}$ ) and enable the effective charge transport via double exchange mechanism (B-O-B) $[68,69]$. A significant influence on the transport properties of the perovskite oxides have both, the degree of filling and the difference of energy between anti-bonding $e_{\mathrm{g}}\left(\sigma^{0 *}\right)$ and $t_{2 \mathrm{~g}}\left(\pi^{\mathrm{O} *}\right)$ orbitals. The transfer integral $\mathrm{I}_{\mathrm{p}-\mathrm{d}}$ is proportional to the cosine of the $\mathrm{B}-\mathrm{O}-\mathrm{B}$ angle, and therefore, the most favorable situation occurs when crystal symmetry is cubic (linear bond) $[68,69]$.

The investigations of the perovskite-type cuprates in order to apply them as the air electrode are limited, especially in the SOEC mode, but published so far for the SOFC configuration present very promising results. For example, Yu et al. reported good chemical compatibility of the tetragonal $\mathrm{La}_{1-\mathrm{x}} \mathrm{Sr}_{\mathrm{x}} \mathrm{CuO}_{2.5-\delta}$ towards yttria-stabilized zirconia (8YSZ) and its high conductivity exceeding around $900 \mathrm{~S} \mathrm{~cm}^{-1}$ at $600{ }^{\circ} \mathrm{C}$. Furthermore, measured cathodic polarization of $\mathrm{La}_{0.7} \mathrm{Sr}_{0.3} \mathrm{CuO}_{2.448}$ is satisfying $(3.8 \mathrm{mV}$ with an applied current density equal to $100 \mathrm{~mA} \mathrm{~cm}{ }^{-2}$ at $850{ }^{\circ} \mathrm{C}$ ) and lower than for the standard $\mathrm{Sr}$-doped $\mathrm{LaMnO}_{3}$ [70,71]. For the following configuration of the lab-scale SOFC: Ni-SDC/SDC/LSCu (where $\mathrm{SDC}-\mathrm{Sm}_{0.15} \mathrm{Ce}_{0.85} \mathrm{O}_{1.925}$ and $\mathrm{LSCu}$ is $\mathrm{La}_{0.7} \mathrm{Sr}_{0.3} \mathrm{CuO}_{3-\delta}$ ) the highest measured power output was $0.12 \mathrm{~W} \mathrm{~cm}^{-2}$ at $800{ }^{\circ} \mathrm{C}$ [72]. In order to decrease polarization resistance and evade influence of TEC mismatch between $\mathrm{Sr}$-doped $\mathrm{LaCuO}_{3-\delta}$ and electrolyte on the cell properties, SDC-LSCu composite cathode was also proposed. For the composition of 25 wt.\% of SDC and $75 \mathrm{wt} \%$ of $\mathrm{LSCu}$ it was possible to reduce polarization two times, comparing to the pure SDC. By using gradually changed composition of the cathode layer $(\mathrm{SDC} / 0.50 \mathrm{LSCu}-0.50 \mathrm{SDC} / 0.75 \mathrm{LSCu}-0.25 \mathrm{SDC} / \mathrm{LSCu})$ the measured polarization resistance was decreased down to $0.094 \Omega \mathrm{cm}^{-2}$ at $800{ }^{\circ} \mathrm{C}$ (from $0.234 \Omega \mathrm{cm}^{-2}$ for LSCu single layer) [70,72-74]. Moreover, in the literature, there are available reports on the ordered $\mathrm{La}_{4} \mathrm{BaCu}_{5} \mathrm{O}_{13+\delta}, \mathrm{La}_{6.4} \mathrm{Sr}_{1.6} \mathrm{Cu}_{8} \mathrm{O}_{20 \pm \delta}$ and $\mathrm{La}_{4} \mathrm{BaCu}_{1-\mathrm{x}} \mathrm{Co}_{\mathrm{x}} \mathrm{O}_{13+\delta}$ as candidate cathode materials for SOFCs, in which characterization of the crystal structure, stability versus commonly used IT-SOFC electrolytes and electrochemical performance can be found $[75,76]$.

\subsection{Layered $\mathrm{Ln}_{2} \mathrm{CuO}_{4 \pm \delta}$ as the possible air electrode}

According to the literature data, the $\mathrm{Ln}_{2} \mathrm{CuO}_{4}$-type materials, with stable +2 oxidation state of $\mathrm{Cu}$ ions, exhibit high thermal stability, as well as low values of TEC. In addition, most of the compounds from the $\mathrm{Ln}_{2} \mathrm{CuO}_{4}$ group are thermomechanically compatible with commercially used ceria-based electrolytes $\left(\mathrm{Ce}_{0.8} \mathrm{Gd}_{0.2} \mathrm{O}_{1.9}-\mathrm{CGO} 20\right)$ even up to $1000{ }^{\circ} \mathrm{C}$ [77]. $\mathrm{Ln}_{2} \mathrm{CuO}_{4 \pm \delta}$ oxides with smaller Ln belong to the mentioned Ruddlesden-Popper series, while $\mathrm{La}_{2} \mathrm{CuO}_{4 \pm \delta}$ is characterized by somewhat different placement of the oxygen anions. The so-called T, $\mathrm{T}^{*}$ and T' phases are well-described in the papers. Generally, the structure of $\mathrm{A}_{2} \mathrm{BO}_{4 \pm \delta}$ allows for a great oxygen nonstoichiometry $( \pm \delta)$ flexibility. Excessive oxygen can be incorporated in a rather rare form of the interstitial species, providing an attractive alternative to the vacancy transport mechanism present in perovskites. This characteristic may be also present in the cuprates. Transport of the interstitial ions, characterized by a low activation energy, can only take place in the rock-salt-ordered layers. Due to structural constraints, both, electronic and ionic transport are of the 2-dimensional type. Electronic transport occurs predominantly in the perovskite-like layers, containing usually transition metal cations, and is also based on B-O-B interactions [67,78,79].

Layered $\mathrm{La}_{2} \mathrm{CuO}_{4 \pm \delta}$ possesses semi-metallic-like electrical conductivity and low TEC value $\left(\sim 12-14 \cdot 10^{-6} \mathrm{~K}^{-1}\right)$ [80]. Often, for different cuprates, the activated type of conductivity is observed, and with a suitable level of $\mathrm{Sr}^{2+}$ doping at A-site, the conductivity can be highly enhanced, e.g. for $\mathrm{La}_{2-x} \mathrm{Sr}_{x} \mathrm{CuO}_{4 \pm \delta}$ values exceeding $100 \mathrm{~S} \mathrm{~cm}^{-1}$ can be obtained [80-83]. Literature reports on the layered, $\mathrm{Cu}$-based oxides applied as the air electrode for SOFC (SOEC) are more numerous, but still remarkably limited in relation to the Co- and Ni-based 
compounds. As reported, very promising electrochemical properties, including chemical and thermal stability with $\mathrm{CGO}$ shows pure and doped $\mathrm{Pr}_{2} \mathrm{CuO}_{4}$. The CGO-supported SOFC with $\mathrm{Pr}_{2} \mathrm{CuO}_{4}$ (as the cathode material) was able to deliver $0.1 \mathrm{~W} \mathrm{~cm}^{-2}$ power density at $800{ }^{\circ} \mathrm{C}$. For $\mathrm{Pr}_{1.95} \mathrm{Ce}_{0.05} \mathrm{CuO}_{4}$ oxide in the configuration of $\mathrm{Ni}-10 \mathrm{Sc} 1 \mathrm{CeSZ} / 10 \mathrm{Sc} 1 \mathrm{YSZ} /$ $\mathrm{CGO} / \mathrm{Pr}_{1.95} \mathrm{Ce}_{0.05} \mathrm{CuO}_{4}$, the cell delivered $0.15 \mathrm{~W} \mathrm{~cm}^{-2}$ at the same temperature $[80,84]$. Interesting electrochemical performance, SOFC output $0.16 \mathrm{~W} \mathrm{~cm}^{-2}$ at $800{ }^{\circ} \mathrm{C}$ with LSGM (lanthanum gallate doped with strontium and magnesium) as electrolyte, was reported for Sr-doped $\mathrm{La}_{2} \mathrm{CuO}_{4}$ [82]. Moreover, Kolchina et al., as well as Li et al. presented its longterm chemical stability with CGO electrolyte and one of the lowest for cuprates ASR values $\left(0.16 \Omega \mathrm{cm}^{2}\right)$ and the lowest cathodic overpotential equal $100 \mathrm{mV}$ at the current density of $150 \mathrm{~mA} \mathrm{~cm}{ }^{-2}$ at $700{ }^{\circ} \mathrm{C}[85,86]$. Similarly to the perovskite cuprates, so far no data on the layered $\mathrm{Ln}_{2} \mathrm{CuO}_{4 \pm \delta}$ tested in the SOEC mode are available.

\subsection{A-site substituted $\mathrm{LaCuO}_{3-\delta}$ as a possible air electrode material}

Partial substitution in the La-site by e.g. $\mathrm{Sr}^{2+}$ or $\mathrm{Ba}^{2+}$ cations enhances thermal and chemical stability of $\mathrm{LaCuO}_{3-\delta}$ with high values of concentration of the oxygen vacancies maintained. The introduction of barium in the La-lattice causes crystallization of the $\mathrm{La}_{0.8} \mathrm{Ba}_{0.2} \mathrm{CuO}_{3-\delta}\left(\mathrm{La}_{4} \mathrm{BaCu}_{5} \mathrm{O}_{15-\delta}, \mathrm{LBC}\right)$ material in the tetragonal structure with $P 4 / m$ space group (Fig. 3a), consisting of quadrangular $\mathrm{CuO}_{5}$ pyramids connected with the $\mathrm{CuO}_{6}$ octahedra, which is stable up to $900{ }^{\circ} \mathrm{C}$ [76]. Introduction to the structure of $\mathrm{Sr}^{2+}$ ions in $\mathrm{La}_{0.75} \mathrm{Sr}_{0.25} \mathrm{CuO}_{3-\delta}\left(\mathrm{La}_{3} \mathrm{SrCu}_{4} \mathrm{O}_{12-\delta}\right.$, LSC) changes space group to $P 4 / \mathrm{mbm}$, with the additional square planar coordination of $\mathrm{Cu}$ ions present (Fig. 3b).

a)

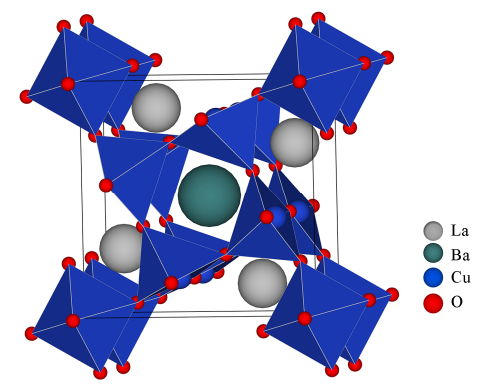

b)

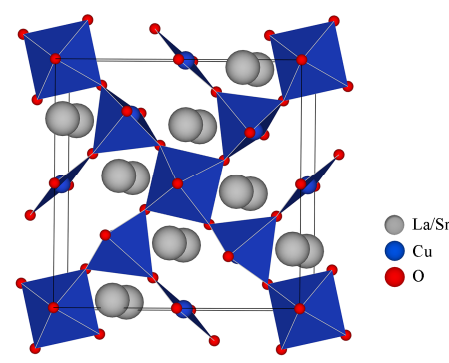

Fig. 3. Visualization of the tetragonal crystal structure of $\mathrm{La}_{4} \mathrm{BaCu}_{5} \mathrm{O}_{15-\delta}$ (a) and $\mathrm{La}_{3} \mathrm{SrCu}_{4} \mathrm{O}_{12-\delta}$ (b).

By substitution of lanthanum ions with $\mathrm{Sr}$ or $\mathrm{Ba}$, it was possible to obtain single phase materials by relatively simple sol-gel method combined with annealing at the ambient pressure of oxygen (air flow) in $900-1000{ }^{\circ} \mathrm{C}$ temperature range. Used in this work techniques and equipment details are analogous to the ones reported in work [82].

Both analyzed compounds exhibit metallic type conductivity, exceeding hundreds of $\mathrm{S}$ $\mathrm{cm}^{-1}$ from room temperature to ca. $800-900{ }^{\circ} \mathrm{C}$, which might be related to the presence of mixed $+2 /+3$ charge states of $\mathrm{Cu}$ cations. Also, a small variation of the oxygen nonstoichiometry can be noticed at elevated temperatures, associated with the appearance of the ionic conductivity. $\mathrm{La}_{4} \mathrm{BaCu}_{5} \mathrm{O}_{15-\delta}$ and $\mathrm{La}_{3} \mathrm{SrCu}_{4} \mathrm{O}_{12-\delta}$ fulfill requirements regarding transport properties for rSOC air electrode. The stability with commonly used LSGM electrolyte was also tested. As shown in Fig. 4, unfortunately, the analyzed materials after short $(24 \mathrm{~h})$ annealing at $1000{ }^{\circ} \mathrm{C}$ react with LSGM electrolyte, and additional phases $\left(\mathrm{La}_{2} \mathrm{CuO}_{4}\right.$-type, $\left.\mathrm{LaSrGa}_{3} \mathrm{O}_{7}\right)$ can be detected. However, both compounds are stable in the same conditions in relation to $\mathrm{La}_{0.2} \mathrm{Ce}_{0.8} \mathrm{O}_{2-\delta}$ (lanthanum doped ceria, LDC), which commonly used as a buffer layer. Consequently, in order to avoid the reaction of the air 
electrode with LSGM electrolyte, the LDC buffer was utilized in the construction of the laboratory-scale cells. As the anode, NiO-LDC composite was used (reduced to Ni-LDC during operation), which also was separated with LDC buffer from LSGM electrolyte in order to minimize possible reactivity.

a)

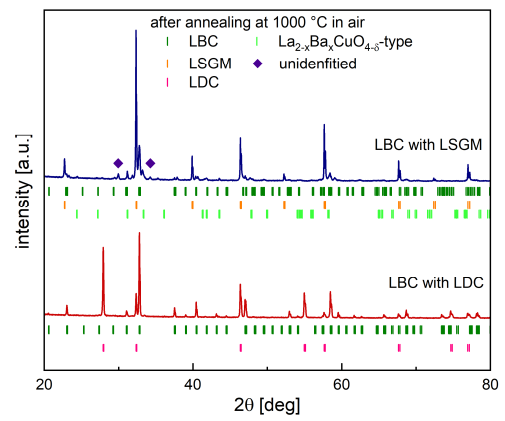

b)

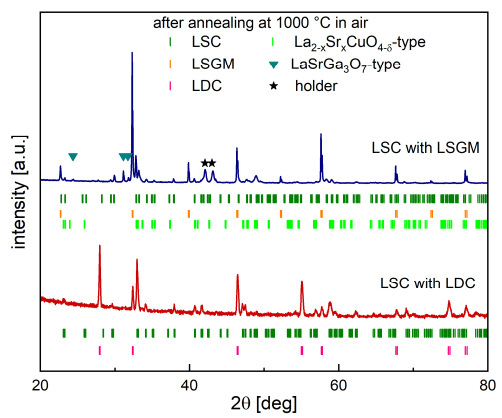

Fig. 4. XRD diffractograms of mixtures (1:1 wt. ratio) of a) LBC-LSGM and LBC-LDC; b) LSC-LSGM and LSC-LDC

The electrochemical impedance spectroscopy (EIS) data were recorded in $600-900{ }^{\circ} \mathrm{C}$ range for the constructed full cells, in which respectively LSC and LBC layers were printed on the LDC buffer. The cells were supplied with wet $\left(3\right.$ vol.\% $\left.\mathrm{H}_{2} \mathrm{O}\right)$ hydrogen (Fig. 5a). In the whole studied range, apart from the ohmic resistance, typical two semi-arcs were observed in the Nyquist plot. As can be seen, the recorded polarization of the full cells in $800-900{ }^{\circ} \mathrm{C}$ range was relatively low. The power densities (Fig. 5b) at the $900{ }^{\circ} \mathrm{C}$ exceeded ca. $0.36 \mathrm{~W} \mathrm{~cm}^{-2}$ for LSC and ca. $0.5 \mathrm{~W} \mathrm{~cm}^{-2}$ for $\mathrm{LBC}$, which are one of the best reported so far values for cells with $\mathrm{Cu}$-based cathodes [87]. The results are comparable with analogous lab-scale SOFCs with layered $\mathrm{La}_{1.5} \mathrm{Sr}_{0.5} \mathrm{CuO}_{4-\delta}$ (LSC) cathode, as presented in [82].

a)

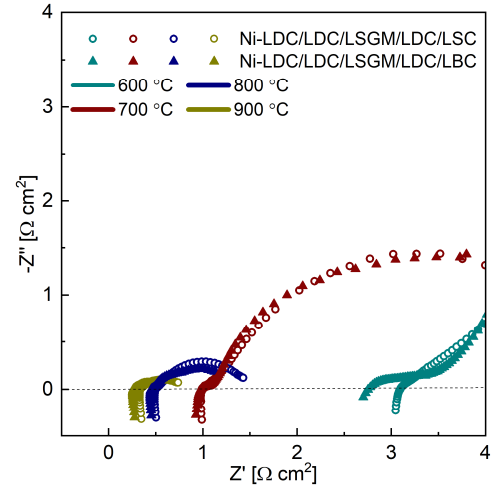

b)

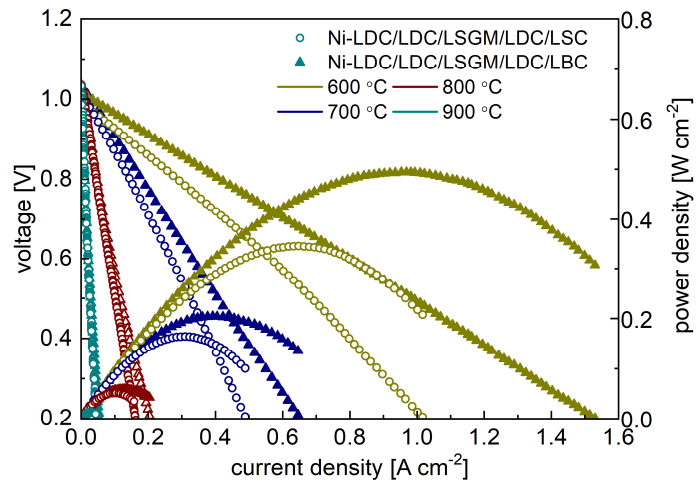

Fig. 5. Performance of lab scale full cells with LSC and LBC as the cathode: a) impedance spectra, b) voltage and power density dependence on the current density [87].

\section{Summary}

Crucial for the SOFCs (and SOECs) development are air electrode materials efficiently working in the lowered temperature range, which require their high catalytic activity and high mixed ionic-electronic conductivity. As shown in the paper, different solutions are currently investigated and mostly compounds based on Co-containing perovskites are 
considered. Nevertheless, to avoid usage of toxic and expensive cobalt, $\mathrm{Cu}$-based oxides with perovskite and perovskite-related structure appear as an interesting alternative.

Acknowledgments: The project was funded by the National Science Centre, Poland on the basis of the decision number UMO-2016-23/N/ST8/00357.

\section{References}

1. REN21, Renewables 2018 global status report, 2018. doi:978-3-9818911-3-3

2. M.Z. Jacobson, M.A. Delucchi, Energy Policy. 39, 1154-1169 (2011)

3. M. McPherson, N. Johnson, M. Strubegger, Appl. Energy. 216, 649-661 (2018)

4. C. Acar, I. Dincer, 1.13 Hydrogen Energy, 2018. doi:10.1016/B978-0-12-8095973.00113-9

5. A. Perna, M. Minutillo et al., Energy Procedia. 101, 1087-1094 (2016)

6. T.A. Adams, J. Nease, et al., Ind. Eng. Chem. Res. 52, 3089-3111 (2013)

7. M.C. Williams, J.P. Strakey, W.A. Surdoval, U.S. Department of Energy's Solid Oxide Fuel Cells: Technical Advances, 300, 295-300 (2010)

8. A. Burke, L. Carreiro, ECS Trans., 35, 2815-2823 (2011)

9. X. Zhang, S.H. Chan et al., J. Power Sources. 195, 685-702 (2010)

10. N. Minh, ECS Trans., 26, 45-50 (2007)

11. F.P. Nagel, et al., Int. J. Hydrogen Energy. 34, 6809-6825 (2009)

12. A. Weber, E. Ivers-Tiffée, J. Power Sources. 127, 273-283 (2004)

13. A.M. Abdalla, S. Hossain et al., Renew. Sustain. Energy Rev. 82, 353-368 (2018)

14. A. Brisse, J. Schefold, M. Zahid, Int. J. Hydrogen Energy. 33, 5375-5382 (2008)

15. A. V. Virkar, G. Tao, Int. J. Hydrogen Energy. 40, 5561-5577 (2015)

16. J.B. Hansen, Faraday Discuss. 182, 9-48 (2015)

17. T. Elmer, M. Worall et al., Renew. Sustain. Energy Rev. 42, 913-931 (2015)

18. J. Mermelstein, O. Posdziech, Fuel Cells. 17, 562-570 (2017)

19. M. Gurz, E. Baltacioglu et al., Int. J. Hydrogen Energy. 42, 23334-23346 (2017)

20. A. Buonomano, F. Calise et al., Appl. Energy. 156, 32-85 (2015)

21. O. Posdziech, K. Schwarze, J. Brabandt, Int. J. Hydrogen Energy. https://doi.org/10.1016/j.ijhydene.2018.05.169 (2018)

22. S. Mukerjee, et al. Solid Oxide Fuel Cell Lifetime and Reliability, (Elsevier Ltd, 2017)

23. T. Ishihara, J. Korean Ceram. Soc. 53, 469-477. (2016)

24. P. Moçoteguy, A. Brisse, Int. J. Hydrogen Energy. 38, 15887-15902 (2013)

25. J. Richter, P. Holtappels et al., Monatshefte Fur Chemie. 140, 985-999 (2009)

26. K.C. Wincewicz, J.S. Cooper, J. Power Sources. 140, 280-296 (2005)

27. Y. Li, R. Gemmen, X. Liu, J. Power Sources. 195, 3345-3358 (2010)

28. S. Miyoshi, A. Takeshita et al., Solid State Ionics. 285, 202-208 (2016)

29. R. Merkle, J. Maier, Angew. Chemie Int. Ed. 47, 3874-3894 (2008)

30. Z. Gao, L. V. Mogni et al., Energy Environ. Sci. 9, 1602-1644 (2016)

31. A. Aguadero, D. Pérez-Coll et al., Chem. Mater. 24, 2655-2663 (2012)

32. G. Bin Jung, C.T. Chang et al., Int. J. Hydrogen Energy. 41, 21802-21811 (2016)

33. Y. Tan, N. Duan et al., J. Power Sources. 305, 168-174 (2016)

34. J. Chen, F. Liang et al., Int. J. Hydrogen Energy. 34, 6845-6851 (2009)

35. A. Olszewska, Z. Du et al., J. Mater. Chem. A. 6, 13271-13285 (2018)

36. A. Tarancón, M. Burriel et al., J. Mater. Chem. 20, 3799-3813 (2010)

37. G. Kim, S. Wang et al., J. Mater. Chem. 17, 2500-2505 (2007)

38. S.Y. Gómez, D. Hotza, Renew. Sustain. Energy Rev. 61, 155-174 (2016)

39. A. Aguadero, L. Fawcett et al., J. Mater. Sci. 47, 3925-3948 (2012) 
40. N. Q. Minh, E.C.S. Transactions, 35, 2897-2904 (2011)

41. L.G.J. De Haart, I.C. Vinke, E.C.S. Transactions, 35, 187-194 (2011)

42. J. Schefold, A. Brisse et al., E.C.S. Transaction 35, 2915-2927 (2011)

43. V.N. Nguyen, Q. Fang et al., Int. J. Hydrogen Energy. 38, 4281-4290 (2013)

44. J.A. Schuler, Z. Wuillemin et al., J. Power Sources. 211, 177-183 (2012)

45. M.J. López-Robledo, et al., J. Power Sources. 378, 184-189 (2018)

46. N.A. Baharuddin, A. Muchtar et al., Int. J. Hydrogen Energy. 42, 9149-9155 (2017)

47. S. Yang, Y. Wen et al., Electrochim. Acta. 267, 269-277 (2018)

48. Q. Zhou, Y. Gao et al., Ceram. Int. 41, 639-643 (2014)

49. S. Cho, Y.N. Kim et al., Electrochim. Acta. 62, 147-152 (2012)

50. J. Yoon, S. Cho et al., Adv. Funct. Mater. 19, 3868-3873 (2009)

51. M. Zhi, S. Lee et al., Energy Environ. Sci. 5, 7066-7071 (2012)

52. Y. Chen, Y. Bu et al., Nano Energy. 26, 90-99 (2016)

53. N.T. Hieu, et al., Mater. Sci. Eng. B 177, 205-209 (2012)

54. A. Enrico, W. Zhang et al., J. Eur. Ceram. Soc. 38, 2677-2686. (2018)

55. F. Li, R. Zeng, L. Jiang, T. Wei, X. Lin, Y. Xu, Y. Huang, J. Mater. 1, 60-67 (2015)

56. F. Wang, W. Li, X. Feng, D. Liu, Y. Zhang, Chem. Sci. 7, 1867-1873 (2016)

57. J.G. Bednorz, K.A. Müller, Zeitschrift für Physik B 64, 189-193 (1986)

58. E. Takayama-Muromachi, Phase Transitions. 41, 37-44 (1993)

59. M.J. Rosseinsky, K. Prassides, Phys. B Condens. Matter. 165-166, 1187-1188 (1990)

60. M. Reehuis, C. Ulrich, K. Prokeš, et al. Phys. Rev. B. 73, 144513 (2006)

61. Z. Hiroi, M. Takano, Nature. 377, 41-43 (1995)

62. J.F. Bringley, B.A. Scott et al., Phys. Rev. B. 47, 15269-15275 (1993)

63. A. Dwivedi, M.A. Rodriguez, et al., J. Am. Ceram. Soc. 7, 1993-1996 (1993)

64. M. Karppinen, H. Yamauchi, T. Ito, et al., Mater. Sci. Eng. B. 41, 59-62 (1996)

65. H. Falcón, M.J. Martinez-Lope et al., Appl. Catal. B Environ. 26, 131-142 (2000)

66. M. Karppinen, H. Yamauchi et al., Phys. C Supercond. Its Appl. 264, 268-274 (1996)

67. A. Chroneos, R. V. Vovk et al., J. Alloys Compd. 494, 190-195 (2010)

68. P. Ganguly, C. Rao, Mater. Res. Bull. 8, 405-412 (1973)

69. A. Glauche, T. Betz, M. Ise, E.C.S. Transactions, 35, 157-165 (2011)

70. H.C. Yu, K.Z. Fung, J. Power Sources. 133, 162-168 (2004)

71. N. Trofimenko, M. Kusnezoff, A. Michaelis, E.C.S. Transactions, 35, 315-325 (2011)

72. M. Zheng, X. Liu, W. Su, J. Alloys Compd. 395, 300-303 (2005)

73. X. Ding, X. Kong et al., Int. J. Hydrogen Energy. 35, 1742-1748 (2010)

74. X. Ding, C. Cui, L. Guo, J. Alloys Compd. 481, 845-850 (2009)

75. S. Duran, J. Tellez et al., Solid State Ionics. 326, 116-123 (2018)

76. M.A. Macias, M. V. Sandoval, et al. Solid State Ionics. 288, 68-75 (2016)

77. Z. Hui, L.I. Qiang, Sci. China Chems. 54, 898-910 (2011)

78. A.C. Tomkiewicz, M. Tamimi et al., J. Mater. Chem. A. 3, 21864-21874 (2015)

79. D. Lee, H.N. Lee, Materials (Basel). 10, 1-22 (2017)

80. K. Zheng, et al., Mater. Res. Bull. 47, 4089-4095 (2012)

81. Z. Zhang, Z. Du et al., Solid State Ionics. 317, 26-31 (2018)

82 A. Niemczyk, A. Olszewska et al., Int. J. Hydrogen Energy. 43, 15492-15504 (2018)

83. Y. Shen, H. Zhao et al., Int. J. Hydrogen Energy. 39, 1023-1029 (2014)

84. L.M. Kolchina, N.V. Lyskov et al., RSC Adv. 6, 101029-101037 (2016)

85. L.M. Kolchina, N.V. Lyskov et al., Mater. Chem. Phys. 165, 91-96 (2015)

86. Q. Li, H. Zhao et al., Electrochem. Commun. 9, 1508-1512 (2007)

87. A. Niemczyk, K. Świerczek, B. Dabrowski, European SOFC \& SOE Forum 2018 Conference materials http://www.efcf.com/fileadmin/content/proceedingsPoC/ Chapter-10_EFCF-2018_Sessions\%20B09-B11_PoC.pdf 